\title{
DESCRIPTION OF STUNTING IN CHILDREN UNDER TWO YEARS WITH THE COMPLEMENTARY FEEDING SUMBANG DISTRICT, BANYUMAS REGENCY, CENTRAL JAVA
}

\author{
Ivan Pratama, Titus Priyo Harjatmo
}

\author{
Jurusan Gizi, Politeknik Kesehatan Jakarta II, Jln Hang Jebat III Blok F3, Jakarta \\ Selatan, Kode Pos 12120
}

E-mail: titoespriyo@yahoo.co.id

Submitted: $24^{\text {th }}$ January 2020; Accepted: $10^{\text {th }}$ June 2020

https://doi.org/10.36525/sanitas.2020.9

\begin{abstract}
One of the nutritional problems in the world is stunting. Stunting is a condition where a toddler has less length or height when compared to age. Stunting is a chronic nutritional problem caused by many factors. One of the factors that can cause stunting is complementary feeding. Infants who are not getting good complementary feeding have a greater chance of growth by 6.5 times compared to babies who get enough complementary feeding. The purpose of this study was to determine the description of stunting in the under two years old by giving complementary feeding in the working area of Puskesmas 1, Sumbang District, Banyumas Regency, Central Java. This descriptive analytic study was taken from secondary data using a cross sectional design conducted on 444 mothers who have children aged 6-23 months in the working area of the District 1 Sumbang Puskesmas. The results showed that there was no significant relationship between nutritional status of under two years on the practice of giving complementary feeding $(p=0.06)$, type of complementary feeding $(p=0.857)$, and frequency of complementary feeding $(p=0.393)$. However, there were differences in nutritional status based on age at the first time giving complementary feeding to under two years whose diet was incomplete $(p=$ $0.001)$ and differences in nutritional status based on the type of complementary feeding given to under two years who washed their hands did not use soap $(p=0.03)$
\end{abstract}

Key Words: stunting, nutritional status, complementary feeding.

This is an open access journal, and articles are distributed under the terms of the Creative Commons Attribution-Non Commercial-Share Alike 4.0 License, which allows others to remix, tweak, and build upon the work non-commercially, as long as appropriate credit is given and the new creations are licensed under the identical terms.

C)2020 Sanitas 


\title{
GAMBARAN STUNTING PADA BADUTA DENGAN PEMBERIAN MP-ASI DI WILAYAH KERJA PUSKESMAS 1 KECAMATAN SUMBANG KABUPATEN BANYUMAS JAWA TENGAH
}

\begin{abstract}
ABSTRAK
Salah satu masalah gizi yang ada di dunia adalah stunting. Stunting merupakan kondisi dimana balita memiliki panjang atau tinggi badan yang kurang jika dibandingkan dengan umur. Stunting merupakan masalah gizi kronik yang disebabkan oleh banyak faktor. Salah satu faktor yang dapat menyebabkan stunting adalah pemberian MP-ASI yang tidak tepat. Bayi yang kurang baik mendapatkan MP-ASI berpeluang lebih besar mengalami gangguan pertumbuhan sebesar 6,5 kali dibandingkan bayi yang mendapatkan MP-ASI secara cukup. Tujuan penelitian ini adalah untuk mengetahui gambaran stunting pada Baduta (Bawah dua tahun) dengan pemberian MP-ASI di wilayah kerja Puskesmas 1 Kecamatan Sumbang, Kabupaten Banyumas, Jawa Tengah. Penelitian ini bersifat deskriptif analitik diambil dari data sekunder menggunakan rancangan cross sectional yang dilakukan pada 444 ibu yang memiliki anak usia 6-23 bulan di wilayah kerja Puskesmas Kecamatan 1 Sumbang. Hasil penelitian menunjukkan bahwa tidak ada hubungan yang bermakna antara status gizi Baduta terhadap praktek pemberian MP-ASI baik dari umur pertama kali pemberian $(p=0,06)$, jenis MP-ASI $(p=0,857)$, dan Frekuensi pemberian MP-ASI $(p=0,393)$. Namun ada perbedaan status gizi berdasarkan umur pertama kali pemberian MP-ASI pada Baduta yang pola makannya tidak lengkap $(p=0,001)$ dan perbedaan status gizi berdasarkan jenis MP-ASI yang diberikan pada ibu Baduta yang cuci tangan tidak menggunakan sabun $(p=0,03)$.
\end{abstract}

Kata Kunci: stunting, status gizi, makanan pendamping ASI

\section{PENDAHULUAN}

Status gizi adalah keadaan yang diakibatkan oleh keseimbangan antara asupan zat gizi dari makanan dengan kebutuhan zat gizi yang diperlukan untuk metabolisme tubuh. Setiap individu membutuhkan asupan zat gizi yang berbeda antar individu, hal ini tergantung pada usia orang tersebut, jenis kelamin, aktivitas tubuh dalam sehari, berat badan, dan lainnya. Ketidakseimbangan antara asupan zat gizi dan kebutuhan tubuh seseorang dapat menyebabkan masalah gizi. Menurut konsep yang dikembangkan oleh United Nation Children's Fund (UNICEF) tahun 1990, masalah gizi disebabkan oleh dua faktor utama, yaitu langsung dan tidak langsung. Penyebab langsung yang menimbulkan masalah gizi adalah kurangnya asupan zat gizi dan penyakit infeksi, sedangkan penyebab tidak langsung yang dapat menimbulkan masalah gizi adalah kurangnya ketersediaan pangan tingkat rumah tangga, perilaku ibu yang kurang, dan kurangnya pelayanan kesehatan dan lingkungan yang tidak sehat.(1)

Salah satu masalah gizi yang ada di dunia adalah stunting. Stunting merupakan kondisi dimana balita memiliki panjang atau tinggi badan yang kurang jika dibandingkan dengan umur. Menurut Joint Child Malnutrition Estimates, Prevalensi stunting di dunia pada tahun 2017 sebesar 22,2\% sedangkan prevalensi stunting di Asia tenggara sebesar 25,7\%.(2) Bawah dua tahun (Baduta) merupakan salah satu 
kelompok umur yang rentan menderita stunting. Data dari hasil pemantauan status gizi (PSG) 2017 menunjukkan prevalensi dari Baduta yang menderita stunting di Indonesia sebesar 20,1\% dengan prevalensi pendek sebesar 13,2\% dan sangat pendek sebesar 6,9\%. Sedangkan di Propinsi Jawa Tengah, prevalensi stunting pada Baduta sebesar 18,4\% dengan prevalensi pendek sebesar 12,9\% dan sangat pendek sebesar 5,5\%.(3) Prevalensi stunting di Banyumas pada tahun 2013 sebesar 33,49\%.(4)

Stunting merupakan sebuah sindrom kegagalan pertumbuhan yang ditandai dengan beberapa gangguan patologis.(5) Stunting berhubungan dengan peningkatan penyakit dan kematian yang disebabkan oleh asupan zat gizi pada bayi yang kurang dan frekuensi bayi terkena infeksi.(6) Stunting menyebabkan anak kehilangan potensi pertumbuhan yang optimal dan menyebabkan postur yang tidak maksimal saat dewasa.(7) Terdapat penelitian yang membuktikan bahwa ada hubungan antara orang dewasa yang pendek dengan produktivitas kerja yang rendah dan pendapatan yang rendah.(8) Stunting juga menyebabkan penurunan perkembangan saraf dan fungsi kognitif sehingga menyebabkan anak mempunyai kemampuan kognitif yang rendah.(9) Stunting menyebabkan peningkatan resiko penyakit kronis pada usia dewasa.(10)

\begin{tabular}{ccc} 
& Tabel 1 Distribusi frekuensi karakteristik Baduta & \\
\hline Karakteristik & $\mathrm{n}$ & $\%$ \\
\hline Jenis kelamin & 211 & \\
Laki- laki & 233 & 47,5 \\
Perempuan & & 52,5 \\
Umur Baduta & 168 & \\
6-12 bulan & 276 & 37,8 \\
13-23 bulan & & 62,2 \\
\hline
\end{tabular}

Stunting merupakan masalah gizi kronik yang disebabkan oleh banyak faktor.(11) Salah satu faktor yang dapat menyebabkan stunting adalah pemberian MP-ASI yang tidak tepat.(12) Bayi yang kurang baik mendapatkan MP-ASI berpeluang lebih besar mengalami gangguan pertumbuhan sebesar 6,5 kali dibandingkan bayi yang mendapatkan MP-ASI secara cukup.(13) Terkadang ada ibu-ibu yang sudah memberikan MP-ASI pada saat bayi berusia dua atau tiga bulan, padahal di usia tersebut kemampuan pencernaan bayi belum siap menerima makanan tambahan. Tidak hanya umur pertama kali pemberian MP-ASI namun jenis MP-ASI, dan 
frekuensi pemberian MP-ASI juga berpengaruh terhadap status gizi pada Baduta. (14-16)

Bayi yang diberikan MP-ASI tidak sesuai dengan waktu pemberian MP-ASI memiliki resiko 2,8 untuk menjadi stunting.(15) Jenis MP-ASI yang diberikan pada bayi juga memengaruhi status gizi bayi. MP-ASI lokal lebih cenderung memberikan status gizi normal bila dibandingkan dengan MP-ASI pabrik.(17) Bayi yang tidak diberikan MP-ASI sesuai rekomendasi, yaitu minimal 3 kali sehari lebih mungkin menjadi stunting jika dibandingkan dengan bayi yang mendapatkan MP-ASI minimal 3 kali sehari.(12) Berdasarkan hasil PSG persentase bayi yang mendapatkan ASI Eksklusif di Indonesia sebesar 35,7\%.(3) Berdasarkan profil kesehatan Propinsi Jawa Tengah persentase bayi yang mendapatkan ASI Eksklusif pada tahun 2017 sebesar $54,4 \%$ dan di Kabupaten Banyumas sebesar 51,8\% yang berarti ada 48,2\% bayi yang sudah diberikan makanan selain ASI sebelum usia 6 bulan.(18) Akibatnya banyak bayi yang mengalami diare. Masalah gangguan pertumbuhan pada usia dini yang terjadi di Indonesia diduga kuat berhubungan dengan banyaknya bayi yang sudah diberi MP-ASI sejak usia satu bulan, bahkan sebelumnya (19).

Penelitian ini bertujuan untuk mengetahui gambaran stunting pada Baduta dengan pemberian MP-ASI di wilayah kerja Puskesmas 1 Kecamatan Sumbang, Kabupaten Banyumas, Jawa Tengah.

Tabel 2 Distribusi frekuensi pemberian MP-ASI

\begin{tabular}{lcc}
\hline Pemberian MP-ASI & $\mathrm{n}$ & $\%$ \\
\hline Umur Pertama Kali Mendapat MP-ASI & 297 & 66,9 \\
$\quad$ Tepat & 147 & 33,1 \\
$\quad$ Tidak Tepat & & \\
Jenis MP-ASI Yang Diberikan & 125 & 28,2 \\
$\quad$ Pangan Lokal & 319 & 71,8 \\
$\quad$ Pabrik & & \\
Frekuensi MP-ASI Yang Diberikan & 175 & 39,4 \\
$\quad$ <3x Sehari & 269 & 60,6 \\
3x Sehari &
\end{tabular}

\section{METODE PENELITIAN}

Data yang digunakan merupakan data dasar di 11 desa di wilayah kerja Puskesmas 1 Kecamatan Sumbang, Kabupaten Banyumas, Jawa Tengah dengan jumlah data sebesar 444 Baduta. Rancangan penelitian menggunakan rancangan survei yaitu rancangan yang tergantung pada jawaban orang terhadap pertanyaan, 
dengan Cross Sectional yaitu variabel dependent dan independent dalam waktu yang sama. Jenis data yang digunakan merupakan data sekunder meliputi karakteristik Baduta dan data pemberian MP-ASI dengan wawancara serta status gizi Baduta $(\mathrm{PB} / \mathrm{U})$ dengan pengukuran antropometri. Data yang telah dikumpulkan kemudian diolah dan disimpulkan menjadi beberapa kategori.

\section{HASIL DAN PEMBAHASAN}

Berdasarkan tabel 1 dapat diketahui karakteristik jenis kelamin laki-laki sebesar 47,5\% dan perempuan 52,5\%. Untuk umur Baduta 6-12 bulan sebesar 37,8\% dan 1323 bulan sebesar $62,2 \%$

Tabel 3 Distribusi frekuensi jenis MP-ASI pangan lokal

\begin{tabular}{|c|c|c|}
\hline Pangan Lokal & $\mathrm{n}$ & $\%$ \\
\hline Bubur Saring & 29 & 23,2 \\
\hline Nasi Tim Saring & 17 & 13,6 \\
\hline Buah Kerok & 74 & 59,2 \\
\hline Pure Kentang & 3 & 2,4 \\
\hline Pure Wortel & 1 & 0,8 \\
\hline Tahu Saring & 1 & 0,8 \\
\hline Jumlah & 125 & 100,0 \\
\hline
\end{tabular}

Berdasarkan tabel 2 dapat diketahui pemberian MP-ASI pada umur yang tepat sebesar $66,9 \%$ dan tidak tepat sebesar 33,1\%, pada MP-ASI jenis pangan lokal sebesar 28,2\% dan jenis pabrik sebesar 71,8\%, pada frekuensi pemberian MP-ASI < $3 x$ sehari sebesar $39,4 \%$ dan $3 x$ sehari sebesar $60,6 \%$.

Berdasarkan tabel 3 dapat diketahui jenis MP-ASI pangan lokal yang diberikan untuk yang paling banyak diberikan yaitu bubur saring $(23,2 \%)$ dan paling sedikit diberikan pure wortel dan tahu saring $(0,8 \%)$.

Tabel 4 Distribusi frekuensi status gizi Baduta

\begin{tabular}{lcc}
\hline Status Gizi & $\mathrm{n}$ & $\%$ \\
\hline Stunting & 102 & 23,0 \\
Normal & 342 & 77,0 \\
& & \\
\hline Jumlah & 444 & 100,0 \\
\hline
\end{tabular}

Berdasarkan tabel 4 dapat diketahui status gizi Baduta yang stunting sebesar $23,0 \%$ dan untuk yang normal sebesar $77,0 \%$. 
Berdasarkan tabel 5 dapat diketahui bahwa nilai $p$ sebesar 0,06 dan bayi dengan status gizi stunting lebih banyak pada pemberian MP-ASI yang tidak tepat $(28,6 \%)$ dan bayi dengan status gizi normal lebih banyak pada pemberian MP-ASI yang tepat (79,8\%). Berdasarkan tabel 5 diketahui nilai $p=0,06(p>0,05)$ yang berarti tidak ada perbedaan status gizi berdasarkan umur pertama kali pemberian. Hasil ini sejalan dengan penelitian yang dilakukan oleh Afiana yang menyatakan bahwa tidak ada hubungan yang bermakna antara umur pertama kali pemberian MP-ASI dengan status gizi $(\mathrm{PB} / \mathrm{U})(20)$, namun hasil ini bertolak belakang dengan penelitian yang dilakukan oleh Dwi Puji, dimana dalam penelitiannya menyatakan bahwa waktu pertama kali pemberian MP-ASI memiliki pengaruh 2,8 kali terhadap kejadian stunting. (15)

Tabel 5 Distribusi frekuensi status gizi Baduta berdasarkan umur pertama kali pemberian MP-ASI

\begin{tabular}{cccccccc}
\hline Umur Pertama & \multicolumn{3}{c}{ Status Gizi (PB/U) } & \multicolumn{2}{c}{ Jumlah } & & p-Value \\
\cline { 2 - 6 } Mali Pemberian & \multicolumn{2}{c}{ Stunting } & \multicolumn{2}{c}{ Normal } & & & \\
\cline { 2 - 6 } & $\mathrm{n}$ & $\%$ & $\mathrm{n}$ & $\%$ & $\mathrm{n}$ & $\%$ & \\
\hline Tepat & 60 & 20,2 & 237 & 79,8 & 297 & 100,0 & 0,06 \\
Tidak Tepat & 42 & 28,6 & 105 & 71,4 & 147 & 100,0 & \\
\hline
\end{tabular}

Berdasarkan tabel 6 dapat diketahui bahwa pada pola makan Baduta yang lengkap, bayi dengan status stunting gizi lebih banyak pada umur pemberian MP-ASI yang tidak tepat $(25,5 \%)$ dan status gizi normal lebih banyak pada umur pemberian MP-ASI yang tepat (75,9\%) dan memiliki nilai $p$ sebesar 0,89 .

Pada pola makan Baduta yang tidak lengkap bayi yang memiliki status gizi stunting lebih banyak pada umur pemberian MP-ASI yang tidak tepat $(36,6 \%)$ dan status gizi normal lebih banyak pada umur pemberian MP-ASI yang tepat $(89,4 \%)$ dan memiliki nilai $p$ sebesar 0,001 .

Berdasarkan tabel 6 diketahui nilai $p$ pada pola makan Baduta yang lengkap sebesar $p=0,89(p>0,05)$ yang berarti tidak ada perbedaan status gizi berdasarkan umur pertama kali pemberian pada Baduta yang pola makannya lengkap, namun nilai $p$ pada pola makan Baduta yang tidak lengkap sebesar $p=0,001(p<0,05)$ yang berarti ada perbedaan status gizi berdasarkan umur pertama kali pemberian MP-ASI pada Baduta yang pola makannya tidak lengkap. Pola makan tidak lengkap yang dimaksudkan adalah susunan hidangan makanan Baduta pada setiap kali makan, 
yaitu harus ada makanan pokok, lauk hewani, lauk nabati, sayur, dan buah. Apabila sudah terdapat minimal 3 komponen sudah dapat dikatakan lengkap. Hasil ini sejalan dengan penelitian yang dilakukan oleh Amodu, yaitu kelengkapan susunan makanan berpengaruh terhadap status gizi Baduta (12). Makanan sehari-hari yang dipilih dengan baik akan memberikan semua zat gizi yang dibutuhkan untuk fungsi normal tubuh. Sebaliknya, bila makanan tidak dipilih dengan baik tubuh akan mengalami kekurangan zat-zat gizi esensial tertentu. Akibat kurang gizi terhadap proses tubuh bergantung pada zat-zat gizi apa yang kurang, namun kekurangan gizi secara umum (makanan dalam kuantitas dan kualitas) pada anak-anak dapat menyebabkan gangguan pertumbuhan tidak optimal, daya tahan tubuh menurun sehingga mudah terserang infeksi, dan juga berpengaruh terhadap perkembangan otak.(21)

Berdasarkan tabel 7 dapat diketahui bahwa nilai $p$ sebesar 0,957 dan bayi dengan status gizi stunting lebih banyak pada jenis MP-ASI pabrik $(23,2 \%)$ dan bayi dengan status gizi normal pada jenis MP-ASI pangan lokal (77,6\%).

Berdasarkan tabel 8 dapat diketahui bahwa pada kebiasaan ibu cuci tangan dengan sabun, bayi dengan status stunting gizi lebih banyak pada jenis MP-ASI pangan lokal $(24,8 \%)$ dan status gizi normal lebih banyak pada jenis MP-ASI pabrik $(80,2 \%)$ dan memiliki nilai $p$ sebesar 0,36 .

Tabel 6 Distribusi frekuensi status gizi Baduta berdasarkan umur pertama kali pemberian MP-ASI pada pola makan Baduta

\begin{tabular}{|c|c|c|c|c|c|c|c|c|}
\hline \multirow{3}{*}{$\begin{array}{c}\text { Kesimpulan } \\
\text { pola makan } \\
\text { Baduta }\end{array}$} & \multirow{3}{*}{$\begin{array}{c}\text { Umur pertama } \\
\text { kali pemberian } \\
\text { MP-ASI }\end{array}$} & \multicolumn{4}{|c|}{ Status gizi $(\mathrm{PB} / \mathrm{U})$} & \multirow{2}{*}{\multicolumn{2}{|c|}{ Jumlah }} & \multirow{3}{*}{ p-Value } \\
\hline & & \multicolumn{2}{|c|}{ Stunting } & \multicolumn{2}{|c|}{ Normal } & & & \\
\hline & & $\mathrm{n}$ & $\%$ & $\mathrm{~N}$ & $\%$ & $\mathrm{n}$ & $\%$ & \\
\hline \multirow{2}{*}{ Lengkap } & Tepat & 51 & 24,1 & 161 & 75,9 & 212 & 100,0 & \multirow{2}{*}{0,89} \\
\hline & Tidak Tepat & 27 & 25,5 & 79 & 74,5 & 106 & 100,0 & \\
\hline Tidak & Tepat & 9 & 10,6 & 76 & 89,4 & 85 & 100,0 & \multirow{2}{*}{0,001} \\
\hline Lengkap & Tidak Tepat & 15 & 36,6 & 26 & 63,4 & 41 & 100,0 & \\
\hline
\end{tabular}

Pada kebiasaan ibu cuci tangan tidak dengan sabun bayi yang memiliki status gizi stunting lebih banyak pada jenis MP-ASI pabrik $(38,6 \%)$ dan status gizi normal lebih banyak pada jenis MP-ASI pangan lokal $(93,7 \%)$ dan memiliki nilai $p$ sebesar 0,03 .

Berdasarkan tabel 8 dapat diketahui nilai $p$ pada kebiasaan ibu cuci tangan dengan sabun sebesar $p=0,36(p>0,05)$ yang berarti tidak ada perbedaan status gizi berdasarkan jenis MP-ASI pada ibu yang cuci tangan dengan sabun, namun nilai $p$ 
pada kebiasaan ibu cuci tangan tidak dengan sabun sebesar $p=0,03(p<0,05)$ yang berarti terdapat perbedaan status gizi berdasarkan jenis MP-ASI pada ibu yang cuci tangan tidak dengan sabun. Menurut Schimdt (2014) dari meta analisis yang telah dilakukan menunjukkan bahwa ada bukti yang menyatakan terdapat hubungan antara hygiene dan sanitasi yang rendah dengan kejadian stunting. (22)

Berdasarkan tabel 9 dapat diketahui bahwa nilai $p$ sebesar 0,393 dan bayi dengan status gizi stunting frekuensi pemberian MP-ASI 3x sehari (24,5\%) dan bayi dengan status gizi normal pada frekuensi pemberian MP-ASI $<3 x$ sehari $(79,4 \%)$.

Berdasarkan tabel 7 didapatkan $p=0,857(p>0,05)$ yang berarti tidak ada hubungan antara Jenis MP-ASI dengan Status Gizi (PB/U). Hasil ini bertolak belakang dengan penelitian yang dilakukan oleh Yusra tahun 2014, yang menyatakan bahwa terdapat hubungan antara jenis pemberian MP-ASI dengan status gizi Baduta.(17)

$\underline{\text { Tabel } 7 \text { Distribusi frekuensi status gizi Baduta berdasarkan jenis MP-ASI yang diberikan }}$

\begin{tabular}{cccccccc}
\hline \multirow{2}{*}{$\begin{array}{c}\text { Jenis MP- } \\
\text { ASI }\end{array}$} & \multicolumn{4}{c}{ Status Gizi (PB/U) } & & \multirow{2}{*}{ Jumlah } & \multirow{2}{*}{ p-Value } \\
\cline { 2 - 5 } & $\mathrm{n}$ & $\%$ & $\mathrm{n}$ & $\%$ & $\mathrm{n}$ & $\%$ & \\
\hline Pangan & 28 & 22,4 & 97 & 77,6 & 125 & 100,0 & \multirow{2}{*}{0,957} \\
Lokal & 74 & 23,2 & 245 & 76,8 & 319 & 100,0 & \\
Pabrik & 74 & & & & & & \\
\hline
\end{tabular}

Berdasarkan tabel 9 diketahui $p=0,393(p>0,05)$ yang berarti tidak ada hubungan antara frekuensi mendapat MP-ASI dengan status gizi (PB/U). Hasil ini bertolak belakang dengan penelitian yang dilakukan oleh Afiani yang menyatakan bahwa terdapat hubungan yang bermakna antara frekuensi pemberian MP-ASI dengan status gizi (PB/U) (20) dan juga bertolak belakang dengan penelitian yang dilakukan oleh Amodu (2016) yang menyatakan bahwa anak yang diberikan MP-ASI $<3 x$ sehari lebih cenderung untuk menjadi stunting. (12)

\section{SIMPULAN}

Status gizi Baduta di wilayah kerja Puskesmas 1 Kecamatan Sumbang yang menderita stunting sebanyak 102 anak $(23,0 \%)$ dan yang status gizi normal sebanyak 342 anak (77,0\%). Pemberian MP-ASI di wilayah kerja Puskesmas 1 Kecamatan Sumbang berdasarkan umur pertama kali diberikan untuk usia $<6$ bulan sebanyak 111 anak (25\%) dan untuk usia $\geq 6$ bulan sebanyak 333 anak (75\%). Berdasarkan 
Jenis MP-ASI yang diberikan untuk pangan lokal sebanyak 125 anak $(28,2 \%)$ dan untuk jenis MP-ASI pabrik sebanyak 319 anak (71,8\%). Berdasarkan frekuensi MPASI yang diberikan untuk $<3$ x sehari sebanyak 175 anak $(39,4 \%)$ dan untuk 3x sehari sebanyak 269 anak (60,6\%). Berdasarkan uji chi-square yang dilakukan terhadap status gizi Baduta dengan praktik pemberian MP-ASI baik dari umur pertama kali Baduta mendapatkan MP-ASI, jenis MP-ASI yang diberikan dan, frekuensi MP-ASI tidak menunjukkan hasil yang signifikan. Setelah dilakukan Setelah dilakukan analisis hubungan umur pertama kali pemberian MP-ASI dengan status gizi pada pola makan Baduta yang tidak lengkap dan analisis hubungan jenis MP-ASI dengan status gizi pada kebiasaan ibu cuci tangan tidak dengan sabun didapatkan hasil yang signifikan.

Tabel 8 Distribusi frekuensi status gizi Baduta berdasarkan jenis MP-ASI yang diberikan pada

\begin{tabular}{|c|c|c|c|c|c|c|c|c|}
\hline \multirow{3}{*}{$\begin{array}{c}\text { Kebiasaan } \\
\text { ibu cuci } \\
\text { tangan }\end{array}$} & \multirow{3}{*}{$\begin{array}{c}\text { Jenis MP- } \\
\text { ASI }\end{array}$} & \multicolumn{4}{|c|}{ Status Gizi (PB/U) } & \multirow{2}{*}{\multicolumn{2}{|c|}{ Jumlah }} & \multirow{3}{*}{$\begin{array}{c}p- \\
\text { Value }\end{array}$} \\
\hline & & \multicolumn{2}{|c|}{ Stunting } & \multicolumn{2}{|c|}{ Normal } & & & \\
\hline & & $\mathrm{n}$ & $\%$ & $\mathrm{n}$ & $\%$ & $\mathrm{~N}$ & $\%$ & \\
\hline \multirow{2}{*}{$\begin{array}{l}\text { Dengan } \\
\text { Sabun }\end{array}$} & Pangan & 27 & 24,8 & 82 & 75,2 & 109 & 100,0 & \multirow{2}{*}{0,36} \\
\hline & Pabrik & 52 & 19,8 & 210 & 80,2 & 262 & 100,0 & \\
\hline \multirow{2}{*}{$\begin{array}{c}\text { Tidak } \\
\text { Dengan } \\
\text { Sabun }\end{array}$} & Pangan & 1 & 8,3 & 15 & 93,7 & 18 & 100,0 & \multirow{2}{*}{0,03} \\
\hline & Pabrik & 22 & 38,6 & 35 & 61,4 & 57 & 100,0 & \\
\hline
\end{tabular}

\section{UCAPAN TERIMA KASIH}

Ucapan terima kasih ditujukan kepada pihak kabupaten Banyumas, Dinas Kesehatan Kabupaten Banyumas, pihak kecamatan Sumbang, desa dan masyarakat desa dalam membantu terlaksananya pengumpulan data ini. 
Tabel 9 Distribusi frekuensi status gizi Baduta berdasarkan frekuensi MP-ASI

\begin{tabular}{|c|c|c|c|c|c|c|c|}
\hline \multirow[t]{3}{*}{ Frekuensi MP-ASI } & \multicolumn{4}{|c|}{ Status Gizi (PB/U) } & \multirow{2}{*}{\multicolumn{2}{|c|}{ Jumlah }} & \multirow{3}{*}{$p$-Value } \\
\hline & \multicolumn{2}{|c|}{ Stunting } & \multicolumn{2}{|c|}{ Normal } & & & \\
\hline & $\mathrm{n}$ & $\%$ & $\mathrm{n}$ & $\%$ & $\mathrm{n}$ & $\%$ & \\
\hline$<3 \mathrm{x}$ sehari & 36 & 20,6 & 139 & 79,4 & 111 & 100,0 & \\
\hline 3x sehari & 66 & 24,5 & 203 & 75,5 & 333 & 100,0 & 0,393 \\
\hline
\end{tabular}

\section{DAFTAR PUSTAKA}

1. Par'i HM, Wiyono S, Harjatmo titus priyo. Penilaian status gizi. In: bahan ajar gizi. Jakarta; 2017.

2. UNICEF, World Health Organization (WHO), World Bank Group (WB).

Levels and trensds in child malnutrition 2018. 2018;15. Available from: http://www.who.int/nutgrowthdb/estimates2017/en/

3. Kementerian Kesehatan RI. Buku Saku Pemantauan Status Gizi Tahun 2017. 2017;140. Available from: http://sehatnegeriku.kemkes.go.id/baca/rilismedia/20170203/0319612/ inilah-hasil-pemantauan-status-gizi-psg-2016/

4. TNP2K. Pemilihan 10 Desa Prioritas di 100 Kabupaten/Kota Prioritas Penanganan Kemiskinan dan. 2017;(November):1-35.

5. Onis M de, Barca F. Childhood Stunting: A Global Perspective. 2016;

6. Olofin I, McDonald CM, Ezzati M, Flaxman S, Black RE, Fawzi WW, et al. Associations of Suboptimal Growth with All-Cause and Cause-Specific Mortality in Children under Five Years: A Pooled Analysis of Ten Prospective Studies. PLoS One. 2013;8(5).

7. Stein AD, Wang M, Martorell R, Norris SA, Adair LS, Bas I, et al. Growth patterns in early childhood and final attained stature: Data from five birth cohorts from low-and middle-income countries. Am J Hum Biol. 2010;22(3):353-9.

8. Hoddinott J, Alderman H, Behrman JR, Haddad L, Horton S. The economic rationale for investing in stunting reduction. Matern Child Nutr. 2013;9(S2):69-82.

9. Prendergast AJ, Humphrey JH. The stunting syndrome in developing countries. Paediatr Int Child Health [Internet]. 2014;34(4):250-65. Available from: http://www.tandfonline.com/doi/full/10.1179/2046905514Y.0000000158

10. Sawaya AL, Martins P;, Hoffman D;, Roberts SB. The link between childhood 
undernutrition and risk of chronic. Nutr Rev [Internet]. 2003;61(5):168-75. Available from:

http://search.proquest.com/docview/212266792/fulltextPDF/5A6C6B8FF5D9 41FDPQ/9?accountid=32506

11. Danaei G, Andrews KG, Sudfeld CR, Fink G, McCoy DC, Peet E, et al. Risk Factors for Childhood Stunting in 137 Developing Countries: A Comparative Risk Assessment Analysis at Global, Regional, and Country Levels. PLoS Med. 2016;13(11):1-18.

12. Udoh EE, Amodu OK. Complementary feeding practices among mothers and nutritional status of infants in Akpabuyo Area, Cross River State Nigeria. Springerplus. 2016;5(1).

13. Rahmad AH Al. Pemberian Asi Dan Mp - Asi Terhadap Pertumbuhan. Pemberian Asi dan Mp-Asi terhadap pertumbuhan Bayi Usia 624 bulan. 2017;17(1):8-14.

14. Kalsum U. Hubungan Umur Pemberian Pertama Makanan Pendamping ASI ( MP-ASI ) dengan Status Gizi Anak 7-36 bulan.

15. Khasanah D puji, Hadi H, Paramashanti B astria. Hubungan antara pemberian makanan pendamping asi (mp-asi) dengan kejadian. Alma Alta Yogjakarta. 2015;

16. Agustina SW, Listiowati E. Hubungan Frekuensi Pemberian Makanan Pendamping Air Susu Ibu ( MP-ASI ) dengan Berat Badan Anak Usia di Bawah Dua Tahun. J Mutiara Med. 2012;12(2):102-8.

17. Yusra. Hubungan Jenis Pemberian Mp-Asi Dengan Status Gizi Anak Usia 612 Bulan Di Puskesmas Darul Kamal Kabupaten Aceh Besar. Univ Syiah Kuala. 2014;

18. Jateng D. Profil Kesehatan Jawa Tengah Tahun 2017. 2017;3511351(24).

19. Mufida L, Widyaningsih TD, Maligan JM. Prinsip Dasar Makanan Pendamping Air Susu Ibu ( MP-ASI ) untuk Bayi 6-24 Bulan : Kajian Pustaka. Basic Principles of Complementary Feeding for Infant 6 - 24 Months : A Review. J Pangan dan Agroindustri. 2015;3(4):1646-51.

20. Rohmani A. Pemberian Makanan Pendamping ASI Pada Anak Usia 1-2 tahuan di Kelurahan Lamper Tengah Kecamatan Semarang Selatan, Kota Semarang, 2010. 
21. Almatsier S. Prinsip Dasar Ilmi Gizi. Gramedia Pustaka Utama. 2010.

22. Schimdt CW. Beyond Malnutrition The Role of Sanitation in Stunted Growth. 2014;122(11):298-303. 